ORIGINAL ARTICLE

\title{
Planning for chemical incidents by implementing a Delphi based consensus study
}

\author{
I W F Crawford, K Mackway-Jones, D R Russell, S D Carley
}

Emerg Med J 2004;21:20-23

This paper provides a practical approach to the difficulties surrounding planning for chemical incidents, based upon the results of a Delphi based consensus study. It is intended to offer advice, which can be implemented at regional and local prehospital and hospital level. The phases of the response that are covered include preparation, management of the incident, delivery of medical support during the incident, and recovery and support after the incident.

$\mathrm{F}$ rom a health service perspective, a chemical incident involves the release of one or more substances that requires special arrangements to be put into place to protect staff, the patient, and the environment. There are about 1300 reported chemical incidents annually in the United Kingdom, most involving less than 10 chemically contaminated casualties. ${ }^{1}$ The top five chemicals involved were chlorine, hydrochloric acid, sulphuric acid, ammonia, and toluene.

As a result of the terrorist attacks in the United States on 11 September 2001 there is now a heightened awareness of the real, but low, threat of chemical terrorism involving the deliberate release of industrial chemicals or chemical warfare agents. Sarin has previously been used as a terrorist weapon in attacks in Matsumoto City and the Tokyo subway, Japan. $^{23}$

In an accompanying paper we have reported the results of a Delphi based consensus study into planning for chemical incidents. ${ }^{4}$ This paper offers practical advice on how general guidance that resulted from that study can be implemented at regional and local prehospital and hospital level. A similar approach has been used previously to improve the care of children ${ }^{6}$ and burns victims ${ }^{78}$ in major incidents.

The aim of this paper is to give practical advice for the preparation, management, and delivery of medical support during the incident, and for the recovery and support phases after the incident. This guidance is intended to undergo local interpretation, and, while not all chemical incidents are major incidents, plans to deal with them must dovetail with existing major incident plans wherever possible.

\section{PREPARATION}

There are three aspects of preparation. These are planning, equipment, and training.

\section{Planning}

Regional planners must ensure that all ambulance services and emergency departments have in place plans for chemical incidents, based upon an annually reviewed local risk assessment.

The principles of risk assessment are to list all identifiable hazards that can cause harm and the harm that can be realised, followed by identifying all people who
Box 1 ltems to be considered when undertaking risk assessment in a catchment area

- What are the use and storage arrangements for chemicals by all industrial sites?

- What are the on-site capabilities of local industrial sites?

- What are the transport arrangements for hazardous substances?

- What are the historical patterns of local chemical incidents?

- What is the population density, taking into consideration the size and position of the major population centres?

- Are all sites accessible within 20 minutes?

- Where are the local watercourses?

- What is the potential for a deliberate release of industrial chemicals or chemical warfare agents?

- Overall risk..

might be harmed by the hazards listed and assessing the actual risk to each. Liaison between the various agencies likely to be involved in a chemical incident will help build up a complete picture. These may include, but should not be restricted to, the emergency services, hospitals, local authority, Health and Safety Executive, Environment Agency, Public Health Laboratory Service, and the chemical industry.

When undertaking risk assessment in a given catchment area, consideration should be given to each of the areas shown in box 1 . The information obtained must be fully documented and a date specified for review, at least on an annual basis. There must be a strategy in place to reduce risk wherever possible.

Planners must take an all risks approach and assume that chemically contaminated casualties may either be dealt with on-scene or may self present directly to emergency departments.

\section{Equipment}

The health service response to a chemical incident requires the provision and appropriate use of chemical personal protective equipment (CPPE), ${ }^{9}{ }^{10}$ to include body, hand, foot, and respiratory protection.

The selection of CPPE for use by health service personnel in a chemical incident is difficult. This is as a result of the diversity of industrial chemicals and chemical warfare agents that might potentially be encountered in an accidental or deliberate release. An all hazards approach must therefore be undertaken. It is particularly important that CPPE for use by 
health service personnel be driven by specification rather than the ability of manufacturers to provide a particular level of protection.

CPPE must be "CE" marked in accordance with the requirements of the amended Personal Protective Equipment (EC Directive) Regulations $1994 .{ }^{11}$ The CE mark signifies that the CPPE has satisfied certain basic safety requirements, and has been type tested and certified by an approved independent body.

To be able to evaluate and directly compare the effectiveness of any given CPPE it is necessary to assess degree of chemical protection afforded. For protective clothing, gloves, and footwear, one aspect of this is achieved by comparing the resistance to permeation of the materials of construction against a list of challenge chemicals. Currently ASTM F1001$99 a^{12}$ is the only available standardised test battery defined for this purpose. The liquid chemicals selected in ASTM F1001-99a are representative of a wide range of chemical agent classes and properties and also take into consideration frequency of use in industrial operations and transport, ease of handling the chemical, hazards of the chemical, and its probable permeability (American Society for Testing and Materials, F1001-99a Standard guide for selection of chemicals to evaluate protective clothing materials).

Currently no standardised test battery exists within the civilian community for testing against chemical warfare agents. Any such a test battery should include, as a minimum, sulphur mustard, VX, and GD. These are broadly representative of mid-volatility vesicants, low and high volatility nerve agents respectively.

CPPE must be disposed of after exposure to chemicals, as it is impossible to quantify the efficacy of any cleaning process and, furthermore, it is possible that the cleaning process may, in itself, change the physical and chemical resistance properties of the equipment.

In addition to CPPE, the appropriate management of a chemical incident also requires the provision of appropriately specified decontamination equipment and facilities. Fixed build decontamination facilities are difficult to design, build, and maintain. Furthermore, the permanent use of fixed build decontamination facilities is difficult to justify as the frequency of chemical incidents is low for most emergency departments. Therefore mobile temporary structures offer a better solution.

The key features for a mobile decontamination facility are that it should:
- Be easily transported by a maximum of two people.

- Be easily erected, by two adequately trained personnel, and ready for use within 15 minutes of arrival on-scene.

- Be "modular" in nature, so that additional "modules" may be used in conjunction with each other to increase capacity as required.

- Provide capability for the decontamination of both ambulant and non-ambulant (stretcher) casualties.

- Be able to accommodate one non-ambulant (stretcher) casualty or two ambulant casualties and up to four NHS personnel wearing CPPE.

- Afford adequate privacy for the chemically contaminated casualty.

- Have a separate entrance and exit.

- Have sufficient space for all necessary additional equipment, for example, basic decontamination equipment, oxygen source, dressings for the control of external haemorrhage, blankets, etc.

In the prehospital environment appropriately specified power and water management systems are also required.

\section{Training}

There should be a national training standard for chemical incidents that should be delivered at local level to all ambulance service personnel and emergency department medical and nursing staff. A national training course, "The structured approach to chemical casualties", ${ }^{12}$ is available in the United Kingdom to meet this requirement.

\section{MEDICAL MANAGEMENT}

Medical management includes command and control of the response, safety aspects, and communication.

\section{Command}

Command structure and responsibilities should follow the same approach as for a major incident-that is, principles of gold, silver, and bronze command apply, with the ambulance command and medical command, if present, in command of the health service response on-scene. ${ }^{10} 13$ The on-scene response should use the concept of zoning - that is, "hot", "warm", and "cold" zones, as shown in figure 1. Only fire service personnel should work within the "hot" zone. Exceptionally, at the request of the fire service HAZMAT officer, where circumstances dictate that advice or assistance

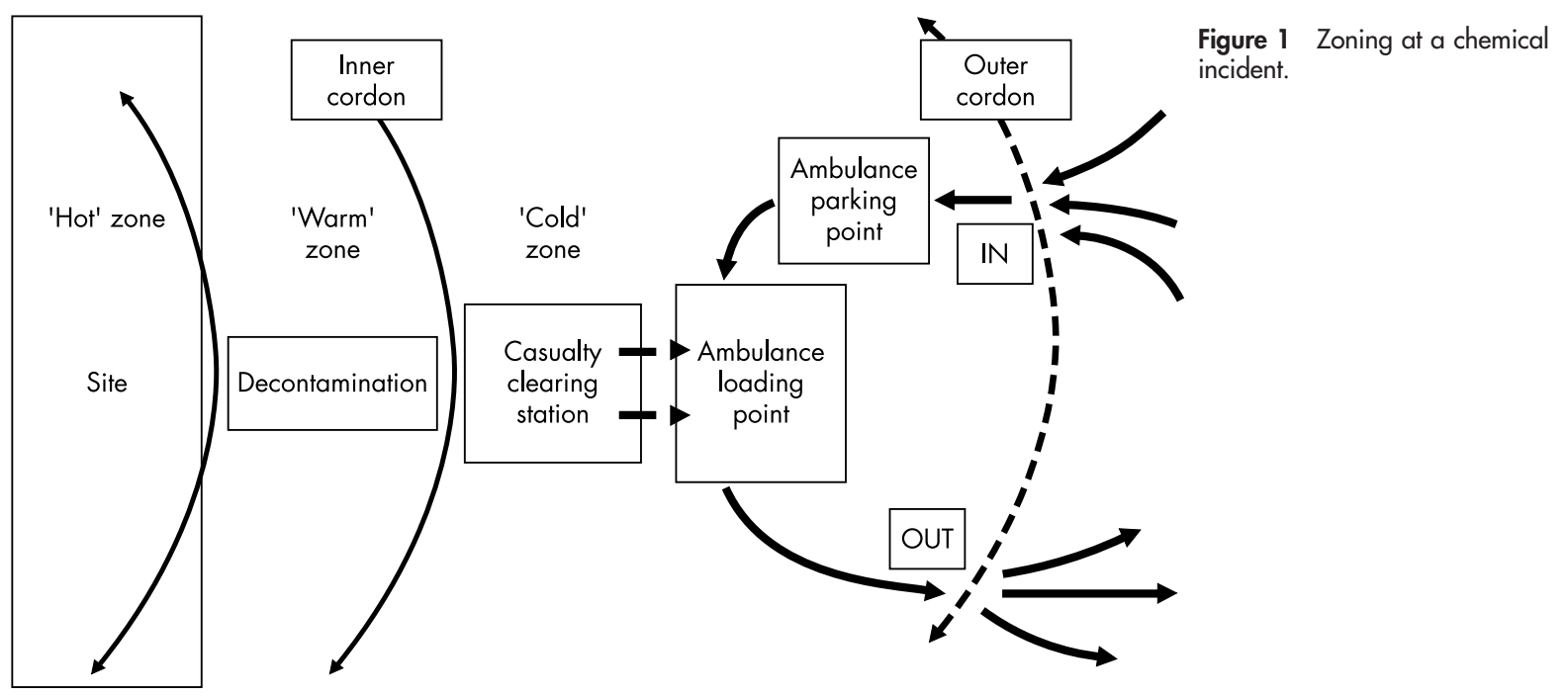


in casualty management is required, health service personnel may be required to enter the "hot" zone. This should only occur under fire service supervision and with the use of CPPE appropriate for the "hot" zone.

\section{Safety}

On-scene safety for health service personnel should be coordinated between the ambulance safety officer and the fire service HAZMAT officer. The incident scene should have limited access and be appropriately cordoned. Once a chemical incident has been declared all non-contaminated, non-protected personnel should be evacuated from the scene. The ambulance safety officer must ensure that all staff within the "warm" zone are adequately protected with appropriate CPPE. Health service personnel will need to be decontaminated, either at the end of the chemical incident or when relieved by another team. Decontamination of health service personnel should proceed by using the "buddy" system followed by the safe removal of decontaminated CPPE.

\section{Communication}

Communication should follow nationally agreed standards for major incidents. Communication links should be established between health service staff on-scene and at the receiving hospital(s), with additional communication links available with specialist units, such as the National Poisons Information Service and the Chemical Incident Provider Units.

\section{MEDICAL SUPPORT}

Medical support in chemical incidents includes triage, treatment, and subsequent transport.

\section{Triage}

A trained chemical triage officer wearing appropriate CPPE should carry out the triage of chemically contaminated casualties within the "warm" zone, using the modified triage

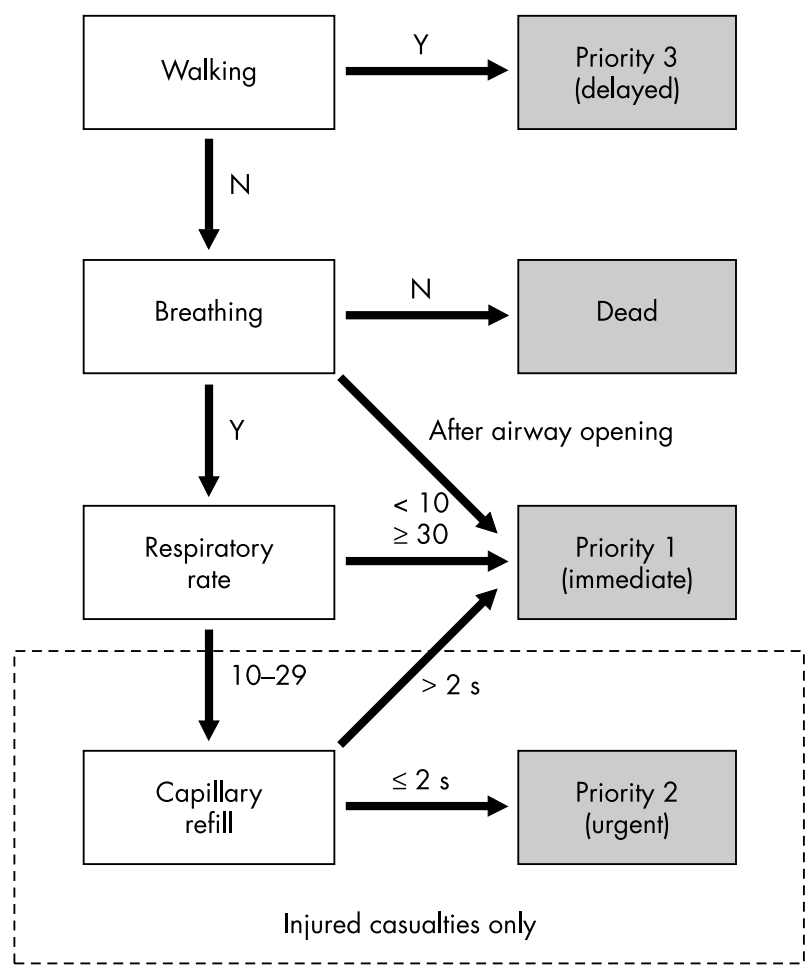

Figure 2 The modified triage sieve. sieve, $^{13}$ as shown in figure 2, to determine priority for decontamination. After decontamination, patients should be triaged again, using specific discriminators as appropriate, and treated in the conventional manner.

The approach to casualties on arrival at hospital should follow the same principles as those outlined above.

\section{Treatment}

Casualties in a chemical incident may be affected as a result of chemical contamination, physical injury or both. Decontamination of chemically contaminated casualties should be viewed as part of the initial treatment, not as an additional process, and should occur as soon as possible, within the "warm" zone and before transport to hospital. The decontamination team carrying out decontamination must wear appropriate CPPE. All items of clothing and personal effects must be removed from chemically contaminated casualties before decontamination, unless medically contraindicated. Attention should be given to the prevention of hypothermia and the preservation of dignity at all times. Before and during the decontamination process, medical treatment should be limited to basic life support measuresthat is, simple airway opening manoeuvres, cervical spine control, bag-valve-mask ventilation, and control of external haemorrhage. Current guidance suggests that water with detergent is the decontaminant of choice for most chemicals.

\section{Box 2 Summary of the "rinse-wipe-rinse"} approach to decontamination

The following equipment is required

- A water source, preferably warm

- A bucket

- Detergent, about $10 \mathrm{ml}$ to one 10 litre bucket of water

- A sponge or soft brush

The decontamination procedure is as follows.

- Non-ambulant casualties should be placed on either a spinal board or aluminium scoop stretcher. Ambulant casualties should stand.

- Decontaminate the facial area before any ventilation equipment is applied. Once the airway is secured the remainder of the acute care procedures can be carried out.

- Remove all items of clothing unless medically contraindicated. Clothing and valuables should be retained in a sealed plastic bag and the police service consulted regarding their evidential value before disposal.

- Rinse the affected areas. This first rinse helps to remove particles and water based chemicals.

- Wipe the affected areas with a sponge or soft brush using a detergent solution. This first wipe helps to remove organic chemicals and petrochemicals that adhere to the skin.

- Rinse for a second time. This second rinse removes the detergent and the chemicals.

- Repeat steps 5 and 6 . The whole process should not take longer than 5-10 minutes.

- When decontaminated the casualty should be passed over the clean/dirty demarcation line onto a clean trolley. Any equipment used during the decontamination process should not pass over the demarcation line. 
The "rinse-wipe-rinse" approach to decontamination should be used. ${ }^{14}$ This is summarised in box 2. After the decontamination process is complete staff should use appropriate "universal" precautions when carrying out medical treatment.

On arrival at hospital, an appropriately trained and protected member of staff should assess all casualties and any found to be chemically contaminated must be decontaminated before entering the emergency department.

In the event of mass casualties who are chemically contaminated and require decontamination, those who are ambulant should be instructed to remove their own clothing. Other improvised methods of delivering high volume, low pressure water should be sought. These could include liaison with the fire service to set up an "emergency decontamination corridor system" or "ladder pipe decontamination system", the use of sprinkler systems in buildings, the use of swimming pools or the use of multiple shower units in other facilities such as schools, hotels, or sports clubs (US Army Soldier and Biological Chemical Command, Guidelines for mass casualty decontamination during a terrorist chemical agent incident)).

\section{Transport}

In a chemical incident, as for any incident, transportation requirements will be dependent upon the numbers of casualties. Chemically contaminated casualties should be decontaminated before transportation. The ambulance service should only be required to transport chemically contaminated casualties in exceptional circumstances. Similarly intrahospital or interhospital transfers should occur only after the patient has been decontaminated. Priority for transport will then be determined as for any non-chemical incident.

\section{Post-incident recovery and support}

Debriefing of all agencies involved in a chemical incident should occur as soon as possible after a chemical incident, with an audit to determine whether the care of patients was optimal. Lessons learnt should be shared nationally and incorporated into future planning.

Occupational exposure monitoring, to be carried out by occupational health, should be available to all staff that require it. This is a requirement if there is evidence of damage to CPPE, penetration and/or permeation of contaminant through CPPE or if there are clinical signs of exposure and dependent upon the chemical involved.

\section{CONCLUSION}

This paper provides a practical approach to the difficult problem of planning for chemical incidents. The principles can be applied to all chemical incidents, whether the consequence of accidental or deliberate release. Local interpretation is required to ensure that the approach described works in practice.

\section{Authors' affiliations}

I W F Crawford, K Mackway-Jones, S D Carley, Department of Emergency Medicine, Manchester Royal Infirmary, Manchester, UK

D R Russell, The National Focus for Chemical Incidents, University of Wales Institute Cardiff (UWIC), Cardiff, UK

Correspondence to: Dr I W F Crawford, Department of Emergency Medicine, Manchester Royal Infirmary, Oxford Road, Manchester M13 9WL, UK; ian.crawford@cmmc.nhs.uk

Accepted for publication 27 January 2003

\section{REFERENCES}

1 The National Focus for Chemical Incidents. Surveillance Report (final quarter 2000 and first quarter 2001). Cardiff: The National Focus for Chemical Incidents, 2001.

2 Nakajima T, Ohta S, Morita H, et al. Epidemiological study of sarin poisoning in Matsumoto City, Japan (published erratum appears in J Epidemiol 1998:8:129). J Epidemiol 1998:8:33-41.

3 Okumura T, Suzuki K, Fukuda A, et al. The Tokyo subway sarin attack: disaster management, Part 1: Community emergency response. Acad Emerg Med 1998;5:613-17

4 Crawford IWF, Mackway-Jones K, Russell DR, et al. Delphi based consensus study into planning for chemical incidents. Emerg Med J 2004;21:24-8.

5 Carley SD, Mackway-Jones K, Donnan S. Delphi study into planning for care of children in major incidents. Arch Dis Child 1999;80:406-9.

6 Mackway-Jones K, Carley SD, Robson J. Planning for major incidents involving children by implementing a Delphi study. Arch Dis Child 1999:80:410-13.

7 Randic L, Carley SD, Mackway-Jones K, et al. Planning for major burns incidents in the UK using an accelerated Delphi technique. Burns 2002;28:405-12.

8 Carley SD, Mackway-Jones K, Randic L, et al. Planning for major burns incidents by implementing an accelerated Delphi technique. Burns 2002;28:413-18

9 HSE. Personal Protective Equipment at Work Regulations, 1992. London: The Stationery Office, 1992

10 Department of Health. Planning for major incidents: the NHS guidance. London: Department of Health, 1998

11 HSE. The Personal Protective Equipment (EC Directive) (Amendment) Regulations, 1994. London: The Stationery Office, 1994.

12 Advanced Life Support Group. The structured approach to chemical casualties, 2nd edn. Manchester: Advanced Life Support Group, 2002.

13 Hodgetts T, Mackway-Jones K, eds. Major incident medical management and support: the practical approach, 2nd edn. London: BMJ Publishing Group, 2002.

14 Fisher J, Morgan-Jones D, Murray V, et al. Chemical incident management for accident and emergency clinicians. London: The Stationery Office, 1999. 